\title{
Decreasing Formaldehyde Emission from Particleboard Panels Fabricated by Adding Newly Phenolic Compounds as a Scavenger to Urea Formaldehyde Resin
}

behzad kord ( $\sim$ behzadkord2014@gmail.com )

Standard Research Institute https://orcid.org/0000-0002-5433-9136

Farnaz Movahedi

Standard Research Institute

Laleh Adlnasab

Standard Research Institute

Nadir Ayrilmis

Istanbul University Cerrahpasa

\section{Research Article}

Keywords: Particleboard, scavenger, formaldehyde emission, technological properties.

Posted Date: June 8th, 2021

DOl: https://doi.org/10.21203/rs.3.rs-560970/v1

License: (1) (1) This work is licensed under a Creative Commons Attribution 4.0 International License.

Read Full License 


\section{Abstract}

This study focused on the influence of some novel scavengers on the physical, mechanical, and formaldehyde emission of particleboard produced with urea-formaldehyde resin. Three different scavengers, alizarin red sulfonate, alizarin yellow-GG, and chromotropic acid, were incorporated to the UF resin at $1,3,5$, and $7 \%$ (by weight) loading levels based on the oven-dried weight of the resin. Other manufacturing parameters were kept constant in the producrion of particleboards. The results indicated that the formaldehyde emission of the particleboards significantly reduced with increasing amount of the scavengers. The lowest formaldehyde emission was found in the specimens containing alizarin red sulfonate $(0.38 \mathrm{mg} / \mathrm{l})$, followed by chromotropic acid $(0.43 \mathrm{mg} / \mathrm{l})$, and alizarin yellow-GG $(0.49 \mathrm{mg} / \mathrm{l})$, respectively, at $7 \mathrm{wt} \%$ loading level of the scavengers. Although the physical and mechanical properties of the particleboards decreased with the increasing content of the scavengers, they met the requirements of particleboards for interior fitments (including furniture) for use in dry conditions (P2 grade) of EN 312 standard. According to the results of technological properties and formaldehyde emission of the particleboards, it can be said that alizarin red sulfonate is the best scavenger among the investigated scavengers.

\section{Introduction}

Wood-based panels are extensively used in the production of furniture all over the world. Among, the wood-based panel industry, particleboard is the most used wood composite panel [1]. The total production of wood-based panel according to the report of European Panel Federation (EPF) was 59.2 million $\mathrm{m}^{3}$ in 2019 . A slight growth, $\left(0.5 \%\right.$ growth to 32.095 million $\mathrm{m}^{3}$, occurred in the production of particleboard in EPF countries. The furniture industry is the largest consumer of the the wood based panels in the EPF countries, accounting for $49 \%$ of overall production, followd by construction industry (38\%) and packaging (3\%) and other applications (10\%), respectively, in Europe in 2019 [1].

Urea-formaldehyde (UF) is the most used synthetic resin in the production of wood-based panels used indoor applications due to its significant advantages such as low-cost, easy supply, transparent color, lower hot pressing temperature, and duration, good mechanical properties of the board in dry conditions [2]. Despite of the mentioned significant advantages, UF resin has two main drawbacks, formaldehyde emission from the board, and low water resistance. UF resin is mainly responsible for the formaldehyde emission from wood-based panels. Formaldehyde is a colorless, toxic, and strong odor used in the production of synthetic adhesives in the panels [2]. The increase in the amount of formaldehyde in the resin will result in higher emissions from the panels. Other significant impacts on the formaldehyde emission from the panels are resin type and its content, hardener type, and its content, hot pressing conditions, mat moisture content, overlaying of the panel, tree species, panel density, and thickness, amount and type of formaldehyde scavengers, environmental conditions (temperature and relative humidity) in service, long periods after the production of the panel $[3,4]$. Wood-based panels are classified according to their emission class such as (from minimum to maximum) super E0, E0, E1, and E2, and E3 class, respectively. Due to the harmful effects of formaldehyde, many countries allow only E1 
and lower emission classes of wood-based panels. The International Agency for Research on Cancer (IARC 2012) classified formaldehyde as a human carcinogen [5]. Besides, increasing awareness of people and legal regulations forced panel and resin manufacturers to drop formaldehyde emission more. One of the easiest ways to decrease the formaldehyde emissions from the wood-based panels is the addition of formaldehyde scavengers into the panel during production.

In literature, there are plenty of studies on decreasing formaldehyde emission from wood-based panels such as plywood, oriented strand board, particleboard, MDF. For example, Cademartori et al. [6] added small percentages of aluminium oxide nanoparticles into UF resin rand investigated thermo-mechanical properties of the composites. They reported that aluminium oxide nanoparticles were effective to reduce the formaldehyde emission (14\%) from MDF based on the results of the desiccator test. Ghani et al. [7] used amines, methylamine, ethylamine and propylamine as formaldehyde catcher. The different amounts $(0.5,0.7$ and $1 \mathrm{wt} \%)$ of each type of amine was incorporated into UF resin and manufactured particleboards with rubberwood particles. The water resistance and mechanical properties of the particleboards were negatively affected by the addition of amines while the formaldehyde emission from the particleboard reduced with the addition of amines. Park and Lee [8] investigated the production of E0 grade UF using titanium dioxide scavenger at $0.5 \%, 1 \%$, and $3 \mathrm{wt} \%$ based on the oven dry weight of UF resin. The results showed that the $1 \mathrm{wt} \%$ addition of titanium dioxide did not a significant effect on the mechanical and physical properties of the particleboards produced with the E0 type UF resin but further increment in the titanium dioxide content decreased the mechanical properties. Costa et al. [9] investigated the effects of sodium metabisulfite, ammonium bisulfite, and urea on the technological properties and formaldehyde emission of particleboard. Among the scavengers, the sodium metabisulfite was the best additive giving the particleboards with zero formaldehyde emission. Dentinho [10] used mesoporous silica nanoparticles, MSNs, as a catalyst into the curing step of urea-formaldehyde (UF) resin synthesis. This synthesis has the huge challenge of reduction of formaldehyde emissions. The ultimate goal of this project was to encapsulate acid inside MSNs pores and coat them with a polymer. This strategy decreased formaldehyde emissions. Krishnamurthy et al. [11] focused on evaluating the dynamic adsorption of formaldehyde over binary mixed metal oxides (MMOs) such as zirconium dioxide/silicon dioxide, titanium dioxide/silicon dioxide with different metal ratios. The zirconia-based composites displayed a comparatively higher affinity to formaldehyde as compared to their titania-based counterparts at very dilute concentrations. The results of the chemical anaysis showed that the formaldehyde was chemically adsorbed by the MMOs after the specimens with the MMOs were exposed to the formaldehyde.

Some natural scavengers such as paper sludge [12], chestnut shell flour [13], condensates obtained from kiln-drying of wood [14], phenolated kraft lignins [15], tannins extractives [16], soy flour [17], and melamine, polyvinyl alcohol, and adipic acid dihydrazide [18] decreased the formaldehyde emission from wood-based panels produced with UF resin.

The present study focused on the potential use of three different novel additives, alizarin red sulfonate, alizarin yellow-GG, and chromotropic acid, as formaldehyde scanvenger for particleboards produced with 
UF resin. An extensive literature search did not show any study on the use of these additives as formaldehyde scavengers for the particleboard. The formaldehyde emission and technological properties of the particleboards were investigated.

\section{Materials And Method 2.1. Wood particles}

Commercially produced wood particles of hardwood tree species such as alder, eucalyptus, poplar, beech, and maple were supplied from Takhte Feshorde Shomal Co, Iran. They were were dried at $80^{\circ} \mathrm{C}$ for $24-\mathrm{h}$ to until a moisture content $(<3 \%)$ based on the oven-dry weight of the particles prior to processing.

\subsection{Resin}

Urea-formaldehyde (UF) resin (E1 grade) in a liquid form was purchased from Tehran Chasbsaz Company, Tehran, Iran. The resin had a solid content of $49 \mathrm{wt} \%$, the density of $1.21 \mathrm{~g} / \mathrm{cm}^{3}$, a viscosity of $15 \mathrm{cp}$, gel time of $55 \mathrm{~s}$, and $\mathrm{pH}$ of 7.5. Ammonium chloride $\left(\mathrm{NH}_{4} \mathrm{Cl}\right)$ solution with a solids content of 20 $\mathrm{wt} \%$ was used as a hardener. As a hardener, $2 \mathrm{wt} \%$ of ammonium chloride solution based on the dry basis of the UF resin was used to increase the curing of the UF resin during the hot pressing. No hydrophobic additive was added into the particleboards.

\subsection{Formaldehyde scavengers}

Three different powder chemical scavengers, alizarin red sulfonate $\left(\mathrm{C}_{14} \mathrm{H}_{7} \mathrm{NaO}_{7} \mathrm{~S}\right.$, a molecular weight of $364.4 \mathrm{~g} / \mathrm{mol})$, alizarin yellow-GG $\left(\mathrm{C}_{13} \mathrm{H}_{8} \mathrm{~N}_{3} \mathrm{NaO}_{5}\right.$, a molecular weight of $\left.309.21 \mathrm{~g} / \mathrm{mol}\right)$, and chromotropic acid $\left((\mathrm{HO})_{2} \mathrm{C}_{10} \mathrm{H}_{4}\left(\mathrm{SO}_{3} \mathrm{Na}\right)_{2} \cdot 2 \mathrm{H}_{2} \mathrm{O}\right.$, a molecular weight of $\left.400.3 \mathrm{~g} / \mathrm{mol}\right)$ were purchased from Sigma-Aldrich Company. The chemical structure of the scavengers is presented in Scheme (Fig. 1). The loading levels of the scavengers incorporated into the UF resin were 1,3,5, and $7 \mathrm{wt} \%$, respectively, based on the ovendried weight of the resin. In this study, the variable factor was 3 types of scavengers at 4 different loading levels. All other factors such as the mixture rate of wood particles, resin and hardener contents, and hot pressing parameters were kept constant to understand the influence of scavenger type and content on the selected properties of the particleboards.

\subsection{Spectroscopic analysis}

An FT-IR spectrometer was used to understand the effect of the functional group on the pure solution of the formaldehyde. The pristine scavenger powders, and the scavenger were mixed with formaldehyde. Fourier transform infrared-Attenuated total reflection (FTIR-ATR) spectroscopy analysis was carried out at ambient temperature within the wavenumber varied from 4000 to $400 \mathrm{~cm}^{-1}$ and a resolution of $4 \mathrm{~cm}^{-1}$. The infrared spectra of the specimens were determined on a Bruker Vertex 70v spectrometer (Germany).

\subsection{Production of particleboards}


All the single-layer particleboards were produced under laboratory conditions. The $10 \mathrm{wt} \% \mathrm{UF}$ resin based on the oven-dry weight of wood particles was applied to the surface of particles in the rotating drum-type blender for $5 \mathrm{~min}$. The particles were hand-formed into mats and then cold-pressed manually. The particleboard mats were hot-pressed at $3 \mathrm{MPa}$ pressure and $170^{\circ} \mathrm{C}$ for $7 \mathrm{~min}$. The hot-press closing rate was $4.5 \mathrm{~mm} / \mathrm{min}$. The target nominal density of the particleboards was $0.7 \mathrm{~g} / \mathrm{cm}^{3}$ and the dimensions of the boards were $300 \mathrm{~mm} \times 300 \mathrm{~mm} \times 15 \mathrm{~mm}$. Ten particleboards were produced for each-treatments. The maximum thickness swelling for particleboard used indoor applications.

\subsection{Test methods}

Test specimens were cut from the particleboards and technological characteristics including formaldehyde emission (desiccator method, ISO 12460-4) [19], modulus of rupture (MOR) [20] modulus of elasticity (MOE) [20], internal bond (IB) strength [21], water absorption [22], and thickness swelling [22] were determined by appropriate standards. Five specimens were used in each test in the experiments. The specimens were kept in the climate room at $20^{\circ} \mathrm{C}$ and relative humidity of $65 \%$ until the constant weight before the tests.

\subsection{Statistical analysis}

An analysis of variance, ANOVA, was used $(p<0.05)$ to deterimine the effect of the scavenger type and content on the mechanical and physical properies of the test specimens prepared from the particleboards. Significant differences among the average values were determined using Duncan's multiple range test with SPSS (version 16).

\section{Results And Discussion \\ 3.1. FTIR analysis}

FT-IR spectra of pure formaldehyde solution, pristine scavenger powders, and the formaldehyde contain scavengers are illustrated in Figs. 2-4. For comparison, the formaldehyde spectrum is presented in all the Figures. The pure formaldehyde solution showed broadband of about $3423 \mathrm{~cm}^{-1}$ for the $\mathrm{O}-\mathrm{H}$ stretching vibration, 2978 and $2919 \mathrm{~cm}^{-1}$ for the $\mathrm{CH}_{2}$ asymmetric and symmetric stretching vibrations, respectively, and $1644 \mathrm{~cm}^{-1}$ for the $\mathrm{C}=0$ saturated aliphatic aldehyde [23]. In Fig. 2(b), the appearance of two peaks at $1673 \mathrm{~cm}^{-1}$ and $1631 \mathrm{~cm}^{-1}$ would be assigned to two $\mathrm{C}=0$ groups of alizarin red-S, while the stretching bands at $1600 \mathrm{~cm}^{-1}$ and $1459 \mathrm{~cm}^{-1}$ exhibited for $\mathrm{C}=\mathrm{C}$ aromatic rings. The absorbance band due to stretching vibrations of $\mathrm{OH}$ groups was observed at $3466 \mathrm{~cm}^{-1}$ [24]. In Fig. 2(c), after interaction with a formaldehyde solution, observation of two peaks belonging to the $\mathrm{CH}_{2}$ groups, along with the disappearance of the sharp peak at $1644 \mathrm{~cm}^{-1}$ due to the $\mathrm{C}=0$ saturated aliphatic aldehyde, verify aldehyde trapping by alizarin red-S.

In Fig. 3(b), the appearance of two peaks at $1649 \mathrm{~cm}^{-1}$ and $1606 \mathrm{~cm}^{-1}$ would be attributed to the scissoring vibrations of the $\mathrm{OH}$ groups and stretching vibrations of $\mathrm{C}=\mathrm{C}$ aromatic rings. The absorbance 
bands at $3530 \mathrm{~cm}^{-1}$ and $3407 \mathrm{~cm}^{-1}$ are related to the $\mathrm{OH}$ groups and intermolecular hydrogen bonging of chromotropic acid [25]. In Fig. 3(c), the observation of formaldehyde addition to the chromotropic acid would be admitted with two absorption bands assigned to asymmetric and symmetric modes of $\mathrm{CH}_{2}$ groups at $2978 \mathrm{~cm}^{-1}$ and $2916 \mathrm{~cm}^{-1}$, respectively.

In Fig. 4(b), the appearance of the absorption band at $1670 \mathrm{~cm}^{-1}$, is due to the $\mathrm{C}=0$ carboxylate group of alizarin yellow-GG. Also, the broadband at $3426 \mathrm{~cm}^{-1}$ comes from the stretching vibration of the $\mathrm{OH}$ group [26]. In Fig. 4(c), the addition of two new bands at $2984 \mathrm{~cm}^{-1}$ and $2925 \mathrm{~cm}^{-1}$ attributed to $-\mathrm{CH} 2$ asymmetric and symmetric vibrations, disclose formaldehyde caught by alizarin yellow-GG.

\subsection{Formaldehyde emission}

The formaldehyde emission of the particleboards depending on the scavenger type and content presented in Fig. 5. The lowest formaldehyde emission was determined for the specimens containing alizarin red-S $(0.38 \mathrm{mg} / \mathrm{l})$, followed by chromotropic acid $(0.43 \mathrm{mg} / \mathrm{l})$, and alizarin yellow-GG $(0.49 \mathrm{mg} / \mathrm{l})$ at $7 \mathrm{wt} \%$ loading level of the scavengers, respectively. Based on the results, it can be said that the alizarin red-S is the most effective scavenger for the particleboards produced. The release of the formaldehyde from all the particleboards decreased as the amount of three scavengers was increased. There was no significance in the formaldehyde emission values when there was a one-step increase in the scavenger content. For example, when the amount of the scavengers increased from 1 to $3 \mathrm{wt} \%$, it was not found a significant decrease in the formaldehyde emission, similarly 3 to $5 \mathrm{wt} \%$, and 5 to $7 \mathrm{wt} \%$ increase ratio, except for the alizarin red-S scavenger for (5 to $7 \mathrm{wt} \%$ ). The formaldehyde emission values of all the particleboards met the requirement of E1 grade $(\max 1.5 \mathrm{mg} /$ ) specified in Japanese standard JIS A 5908 [27] at all loading levels of three scavengers. Besides, the particleboards containing the 5 and $7 \mathrm{wt} \%$ of three scavengers met the requirement of E0 grade ( $\max 0.5 \mathrm{mg} / \mathrm{l}$ ) of the JIS A 5908. As shown in Fig. 5 , the addition of scavengers with aromatic rings decreases the density of methylene bonds in the ureaformaldehyde resin chain and consequently reduced the amount of formaldehyde emission from the samples.

The probable mechanisms for reducing formaldehyde emission from particleboards using scavenger agents are presented in Scheme (Fig. 6). The high affinity of alizarin red-S towards emitted formaldehyde molecules comes from the presence of the two adjacent phenolic hydroxyl groups $(-\mathrm{OH})$ on the aromatic ring, which accelerates nucleophilic addition reaction. Indeed, the non-bonded electron lone pair $\mathrm{OH}$ groups attack carbonyl groups $(\mathrm{C}=\mathrm{O})$ in formaldehyde, forming a methylol structure $\left(\mathrm{RO}-\mathrm{CH}_{2}-\mathrm{OH}\right)$. Then, the reaction proceeds through the attack of the other lone pair that existed on the adjacent ring-OH to methylol group via an intrarmolecular interaction. The proper stereochemistry of these two phenolic hydroxyls towards free formaldehyde molecules concludes in a suitable fine-membered ring structure in (Scheme 2, I) (Fig. 6.). In the case of chromotropic acid, because of the ortho and para directing capability of phenolic hydroxyl groups, any substitution reaction would occur through the orthoand para positions of the phenolic hydroxyl groups on aromatic rings. Thus, formaldehyde interaction with chromotropic acid on the ortho position concludes in structure (Scheme 2, II), while nucleophilic addition on the para 
site attains compound (Scheme 2, III) (Fig. 6). Both of the proposed mechanisms endure methylol group's formation, at the first step, which further undergoes to create methylene $(\mathrm{CH} 2)$ bridges in a 2:1 mole ratio of chromotropic acid to formaldehyde, respectively [28]. In alizarin yellow GG, based on its structure with only one electron-donating group (phenolic hydroxyl group) and two electron-withdrawing groups on the aromatic ring, the nucleophilic attack site limited. Electron-donating groups are directing of ortho and para, while electron-withdrawing groups are directing meta. Thus, trapping the free formaldehyde would occur on the more active ortho position of the phenolic group that its position towards the other two electron-withdrawing groups is meta. Based on the explained mechanism, alizarin yellow GG reacts with free emitted formaldehyde in a 2:1 molar ratio, obtaining the compound (Scheme 1, IV) (Fig. 6).

In comparison, the best results of reducing formaldehyde emission from particleboards are achieved by applying alizarin red-S, in which acts through an acceptable size-ring formation (five-membered ring). Next, chromotropic acid with the possibility of having two sites for nucleophilic addition seems to be a better candidate for trapping the formaldehyde than alizarin yellow GG.

\subsection{Mechanical properties}

The bending properties of the particleboards decreased with the increasing amount of the scavenger. The highest MOR was found in the specimens containing alizarin red-S, followed by alizarin yellow-GG, and chromotropic acid, respectively (Fig. 7). As the amount of the alizarin red-S increased from 1 to $7 \mathrm{wt} \%$ in the particleboard, the MOR decreased from 18.7 to $14.7 \mathrm{MPa}$. A similar trend was observed for alizarin yellow-GG (18 to $14.1 \mathrm{MPa}$ ) and chromotropic acid (17.4 to $13.6 \mathrm{MPa}$ ). The MOR of all the particleboards met the minimum requirement (11 MPa) of particleboards for interior fitments (including furniture) for use in dry conditions (P2 grade) specified in EN 312 [28]. Statistical analysis $(p<0.05)$ found significant differences among the treatments. As the amount of the alizarin red-S and chromotropic acid increased from 1 to 5 in the particleboard, there was no significant decrease in the MOR, but further increment ( 7 wt\%) significantly decreased the MOR. As for the alizarin yellow-GG, all the particleboards showed significant differences in the MOR at four loading levels.

The MOE of the particleboards decreased with the increasing amount of the scavenger (Fig. 8). As the amount of all the scavengers increased from 1 to $5 \mathrm{wt} \%$ in the particleboard, the MOE of the specimens significantly decreased, but further increment (7 wt\%) did not significantly decrease the MOE of the specimens containing the alizarin red-S and alizarin yellow-GG, except for the chromotropic acid decreased the MOE. As for the alizarin yellow-GG, all the particleboards showed significant differences with each other in the MOE at four loading levels. The MOE of all the particleboards met the minimum requirement $(1600 \mathrm{MPa}$ ) of particleboards for interior fitments (including furniture) for use in dry conditions (P2 grade) [29].

The IB strength of the specimens is presented in Fig. 9. The IB results showed a similar trend to the bending properties. The highest internal bond strength was found in the specimens containing alizarin red-S (0.91 MPa), followed by alizarin yellow-GG (0.87 MPa), and chromotropic acid (0.83 MPa) at $1 \mathrm{wt} \%$ scavenger level, respectively. The IB strength of the specimens produced with all the scavengers 
decreased when the amount of the scavengers increased from 1 to $7 \mathrm{wt} \%$. According to the results of Duncan's multiple range analysis, the alizarin red-S and alizarin yellow-GG showed similar significant differences. As the scavenger content increased from 1 to $3 \mathrm{wt} \%$, the IB strength of both particleboard types significantly decreased, but there was no significant difference was observed when the scavenger content increased from 3 to $5 \mathrm{wt} \%$, and 5 to $7 \mathrm{wt} \%$, respectively. As for the chromotropic acid, a significant decrease was observed when the scavenger content increased from 1 to $3 \mathrm{wt} \%$ while no significant difference was not found as it increased from 5 to $7 \mathrm{wt} \%$. The IB strength of all the particleboards met the minimum requirement $(0.35 \mathrm{MPa})$ of particleboards for interior fitments (including furniture) for use in dry conditions (P2 grade) [29].

In the case of mechanical properties, the addition of scavengers noticeably reduced the bond quality between the wood particles as shown in the results of the IB strength. It is the most sensitive characteristic affected highly from the crosslinking rate of the resin network [30]. The test results informed that the crosslinking of the cured resin was negatively affected by the addition of scavengers with the aromatic rings due to their intervention to the crosslinking. The decrease in the bending properties and IB strength could be explained by the pre-consumption of formaldehyde by amines dispersed in the network of the cured resin [9]. As the amount of the free-formaldehyde content was reduced in the UF resin, the the crosslinking degree of the cured resin decreased, which gave the lower technological properties. The results showed that the degree of the curing reaction of the aminecontaining UF resin were negatively affected by the increasing content of scavengers. Furthermore, the numbers of the cross-linked structures in the cured resin decreased with the addition of scavengers. The severity of the curing degree was dependent on the scavenger type. Consequently, the the bond performance between the wood particles was adversely affected, which reduced the mechanical properties. The IB strength of the specimens were still above the minimum value of the standard.

\subsection{Physical properties}

Thickness swelling and water absorption of the particleboards produced with UF resin containing different amounts of scavengers are displayed in Figs. 10 and 11, respectively. The lowest thickness swelling and water absorption were found in the specimens with alizarin red-S, followed by alirazin yellow-GG, and chromotropic acid, respectively. As the amount of the scavengers was increased from 1 to $7 \mathrm{wt} \%$ in the particleboard, the thickness swelling increased from 10.25 to $13.80 \%$ for alizarin red-S, from 10.89 to 14.19 for alizarin yellow-GG, and 11.28 from to 14.77 chromotropic acid. The maximum thickness swelling for non load-bearing particleboards for use in humid conditions (P3 grade) specified in EN 312 is $14 \%$ (thickness range: 13 to $20 \mathrm{~mm}$ ). The particleboards containing alizarin red-S up to $7 \mathrm{wt} \%$ met the maximum value of EN 312 standard [29]. However, the maximum thickness swelling for the particleboards containing alizarin yellow-GG and chromotropic acid was determined at $5 \mathrm{wt} \%$ content instead of $7 \mathrm{wt} \%$. A similar trend to the thickness swelling was observed for the water absorption. As seen in Fig. 11, water absorption values ranged from 30 to $50 \%$ depending on the scavenger type and content.

In the case of physical properties, the increase in the thickness swelling and water absorption of the particleboards containing the scavenger might be correlated to the reduction in IB strength of the 
particleboard produced with UF resin containing aromatic ring [8]. The improvement in the IB strength directly corelated to the dimensional stability of the particleboard because better bondline among the wood particles holds them tightly and gave lower thickness swelling and water absorption.

\section{Conclusion}

The potential use of some additives as formaldehyde scavengers were investigated in the production of particleboard which is the most used wood-based panel in the furniture industry. The results of this study clearly showed that the studied scavengers significantly decreased the formaldehyde emission of the particleboard. According to the formaldehyde emission results from the particleboards, the best scavenger was alizarin red sulfonate $(0.38 \mathrm{mg} / \mathrm{l})$, followed by chromotropic acid $(0.43 \mathrm{mg} / \mathrm{l})$, and alizarin yellow-GG $(0.49 \mathrm{mg} / \mathrm{l})$, respectively. The formaldehyde emission from the wood-based panels decreased with the increasing content of the scavengers. Although the physical and mechanical properties of the particleboards decreased with the increasing content of the scavengers, they met the requirements of particleboards for interior fitments (including furniture) for use in dry conditions (P2 grade) of EN 312 standard. Based on the results of the physical and mechanical properties, and formaldehyde emission, it can be said that Alizarin red sulfonate can be efficiently used in the production of particleboards produced with UF resin, especially for nursery furniture.

\section{Declarations}

\section{Acknowledgement}

This work was supported by the Standard Research Institute (Project number: 98054). The authors wish to acknowledge Standard Research Institute for financial support.

\section{References}

1. EPF (2020) Wood-based panel production declined in 2019, Wood based panels Int. https://www.wbpionline.com/news/epf-stats-show-wood-based-panel-production-declined-in-20198030459

2. Ryu DY, Shimohara T, Nakabayashi K, Miyawaki J, Park J, Yoon SH (2019) Urea/nitric acid coimpregnated pitch-based activated carbon fiber for the effective removal of formaldehyde. J Ind Eng Chem 80: 98-105

3. Nemli G, Öztürk I (2006) Influences of some factors on the formaldehyde content of particleboard. Build Environ 41: 770-774

4. Ayrilmis N, Lee YK, Kwon JH, Han TH, Kim HJ (2016) Formaldehyde emission and VOCs from LVLs produced with three grades of urea-formaldehyde resin modified with nanocellulose. Build Environ 97: 82-87 
5. IARC (2012) Chemical agents and related occupations: A review of human carcinogens. Iarc monographs on the evaluation of the carcinogenic risks to humans. Lyon, France

6. Cademartori PHG, Artner MA, De Freitas RA, Esteves Magalhães WL (2019) Alumina nanoparticles as formaldehyde scavenger for urea-formaldehyde resin: Rheological and in-situ cure performance. Compos Part B 176: 107281-107290

7. Ghania A, Ashaaria Z, Bawona P, Lee SH (2018) Reducing formaldehyde emission of urea formaldehyde-bonded particleboard by addition of amines as formaldehyde scavenger. Build Environ 142: 188-194

8. Park HS, Lee HH (2009) A novel manufacturing method of urea-formaldehyde resin with the titanium dioxide for reducing formaldehyde emission. Jour Agri Sci 36: 11-18

9. Costa NA, Pereira J, Ferra J, Cruz P, Martins J, Magalhaes FD, Mendes A, Carvalho LH (2013) Scavengers for achieving zero formaldehyde emission of wood-based panels. Wood Sci Technol 47: $1261-1272$

10. Dentinho IV (2017) Formaldehyde-scavenging nanoparticles for high performance resins. Instituto Superior Técnico, 1-19

11. Krishnamurthy A, Thakkar H, Rownaghi AA, Rezaei F (2018) Adsorptive removal of formaldehyde from air using mixed-metal oxides. Ind Eng Chem Res 57: 12916-12925

12. Migneault S, Koubaa A, Riedl B, Nadji H, Deng J, Zhang S (2011) Potential of pulp and paper sludge as a formaldehyde scavenger agent in MDF resins. Holzforschung 65: 403-409

13. Ayrilmis N, Kaymakci A (2012) Reduction of formaldehyde emission from light MDF panels by adding chestnut shell flour. Holzforschung 66: 443-446

14. Ayrilmis N, Kapti T, Gürel A, Ohlmeyer M (2018) Reducing formaldehyde emission from wood-based panels by modification of UF and MUF resins with condensates obtained from kiln-drying of wood. Holzforschung 72: 753-757

15. Kordkheili HY, Pizzi A, Niyatzade G (2016) Reduction of formaldehyde emission from particleboard by phenolated kraft lignin.J Adhes 92:485-497

16. Neimsuwan T, Siramon P, Hengniran P, Punsuvon V (2017) Effect of tannin addition as a bioscavenger on formaldehyde content in particleboard. J Trop For Res 1: 45-56

17. Taghiyari HR, Hosseini SB, Ghahri S, Ghofrani M, Papadopoulos AN (2020) Formaldehyde emission in micron-sized wollastonite-treated plywood bonded with soy flour and urea-formaldehyde resin. Appl Sci 10: 6709-6723

18. Liu K, Su C, Ma W, Li H, Zeng Z, Li L (2020) Free formaldehyde reduction in urea-formaldehyde resin adhesive: Modifier addition effect and physicochemical property characterization. BioRes 15: 23392355.

19. ISO 12460-4 (2016) Wood-based panels, determination of formaldehyde release-Part 4: Desiccator method. International Organization for Standardization, Geneva, Switzerland 
20. EN 310 (1993) Wood based panels, determination of modulus of elasticity in bending and bending strength. European Committee for Standardization, Brussels, Belgium

21. EN 319 (1993) Particleboards and fiberboards, determination of tensile strength perpendicular to the plane of the board. European Committee for Standardization, Brussels, Belgium

22. EN 317 (1993) Particleboard and fiberboards, determination of tensile strength perpendicular to the plane of the board. European Committee for Standardization, Brussels, Belgium

23. Alkhalf MI, Mirghani MES (2017) Detection of formaldehyde in cheese using FTIR spectroscopy. Int J Food Res Technol 24: 496-500

24. Moriguchi T, Yano K, Nakagawa S, Kaji F (2003) Elucidation of adsorption mechanism of bonestaining agent alizarin red S on hydroxyapatite by FT-IR microspectroscopy. J Colloid Interf Sci 260: 19-25

25. Pal A, Dey TK, Debnath AK, Bhushan B, Sahu AK, Bindal RC, Kar S (2017) Mixed-matrix membranes with enhanced antifouling activity: probing the surface-tailoring potential of Tiron and chromotropic acid for nano-TiO2. Royal Soc Open Sci 4: 170368-170375

26. Nigam N, Kumar S, Dutta PK, Ghosh T (2015) Studies on thermo-optic property of chitosan-alizarin yellow GG complex: a direction for devices for biomedical applications, J Bull Math Sci 38: 16391643

27. JIS A 5908 (1994) Particleboards, Japanese Standards Association (JSA), Tokyo, Japan

28. Fagnani E, Melios CB, Pezza L, Pezza HR (2003) Chromotropic acid-formaldehyde reaction in strongly acidic media, The role of dissolved oxygen and replacement of concentrated sulphuric acid. Talanta 60: 171-176

29. EN 312 (2010) Particleboards-specifications. European Committee for Standardization, Brussels, Belgium

30. Siimer K, Kaljuvee T, Christjanson P, Lasn I (2006) Curing of urea-formaldehdye resins on a wood substrate. J Therm Anal Calorim 84: 71-77

\section{Figures}




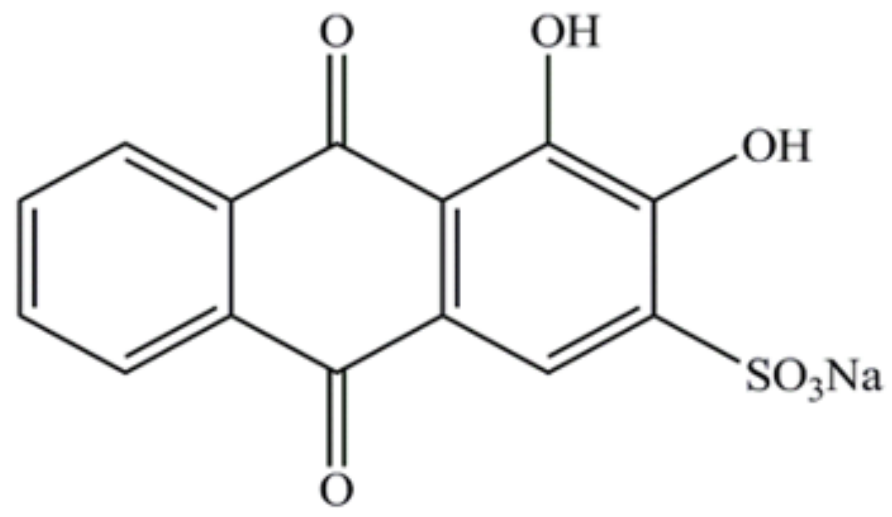

a) Alizarin Red $\mathrm{S}$

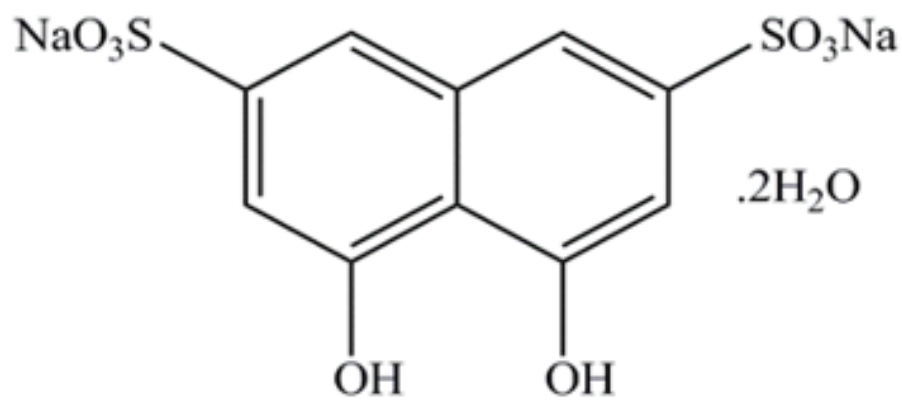

b) Chromotropic acid disodium salt dihydrate

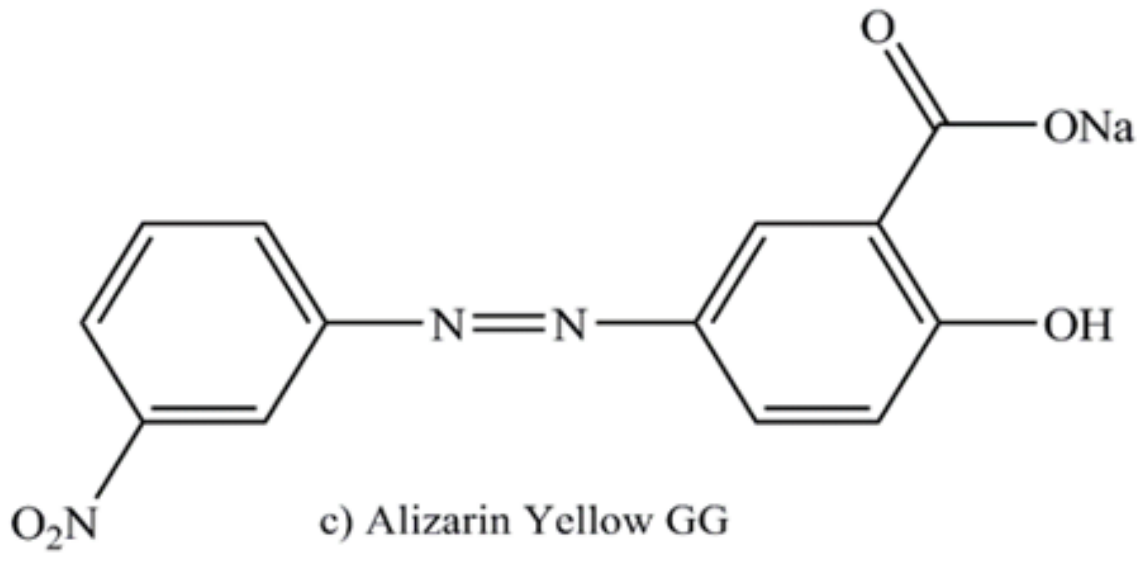

Figure 1

Scheme of chemical structure of scavengers. 


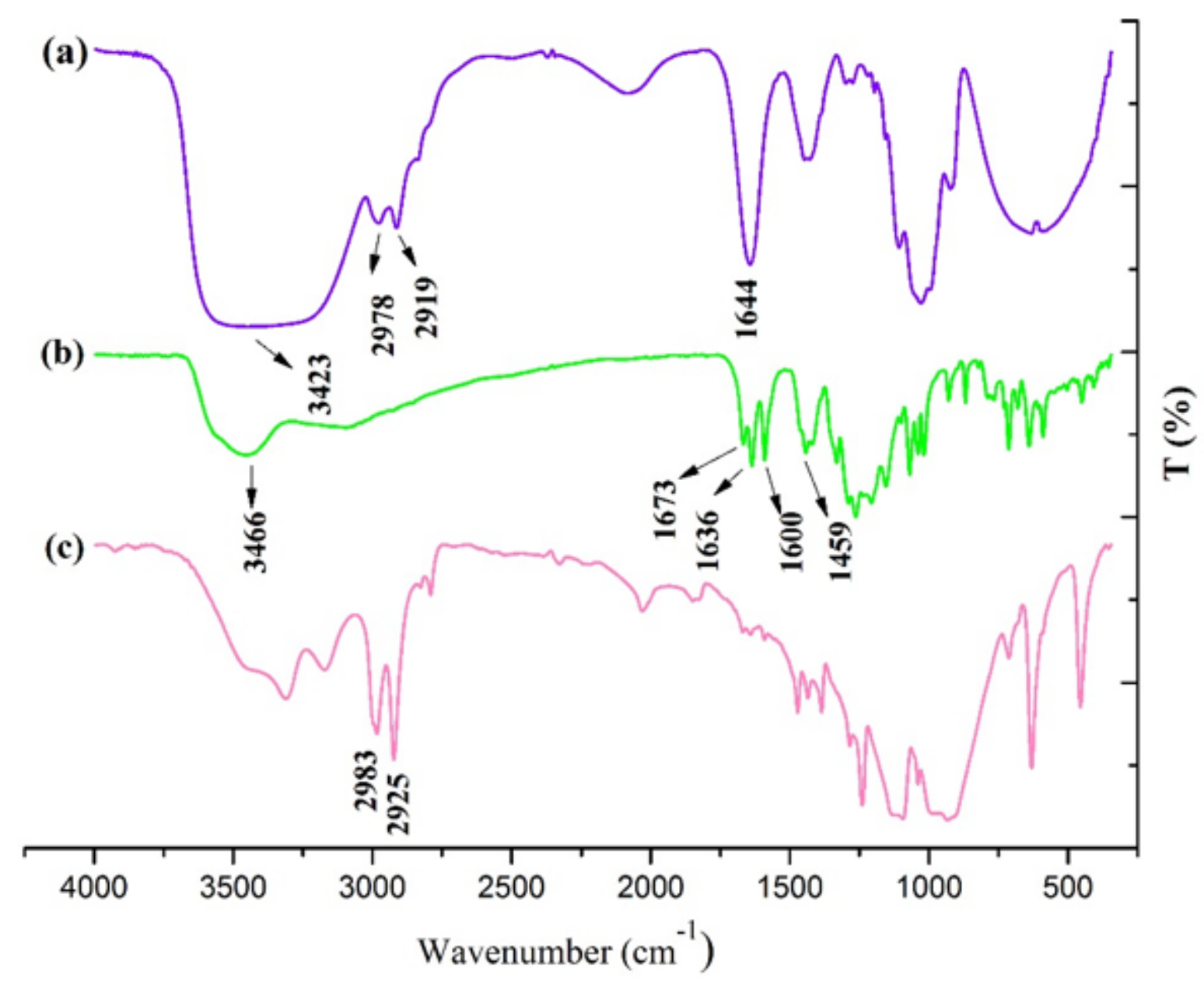

Figure 2

FTIR spectra of (a) formaldehyde, (b) alizarin red-S, (c) formaldehyde mixed with alizarin red-S. 


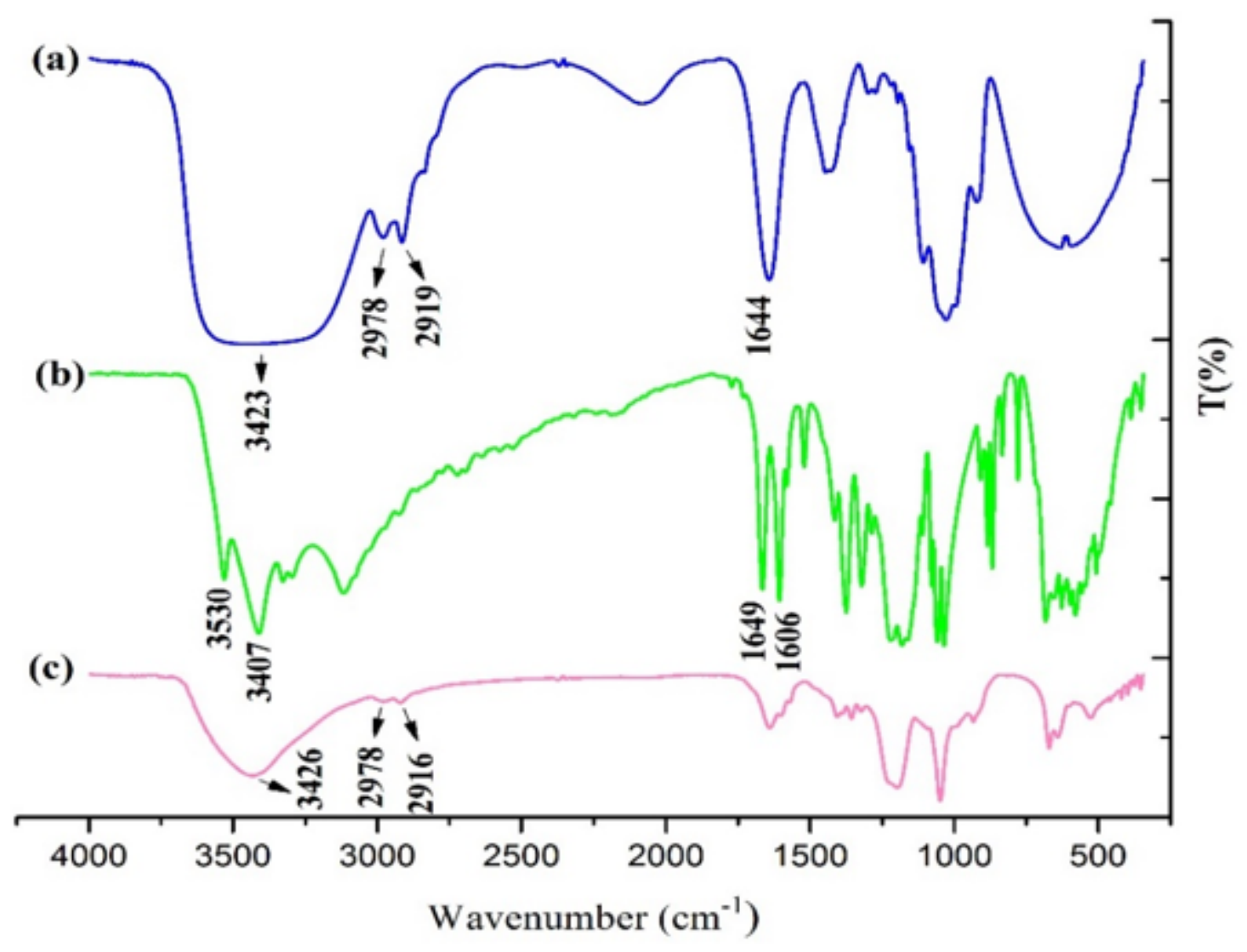

Figure 3

FTIR spectra of (a) formaldehyde, (b) chromotropic acid, (c) formaldehyde mixed with chromotropic acid. 


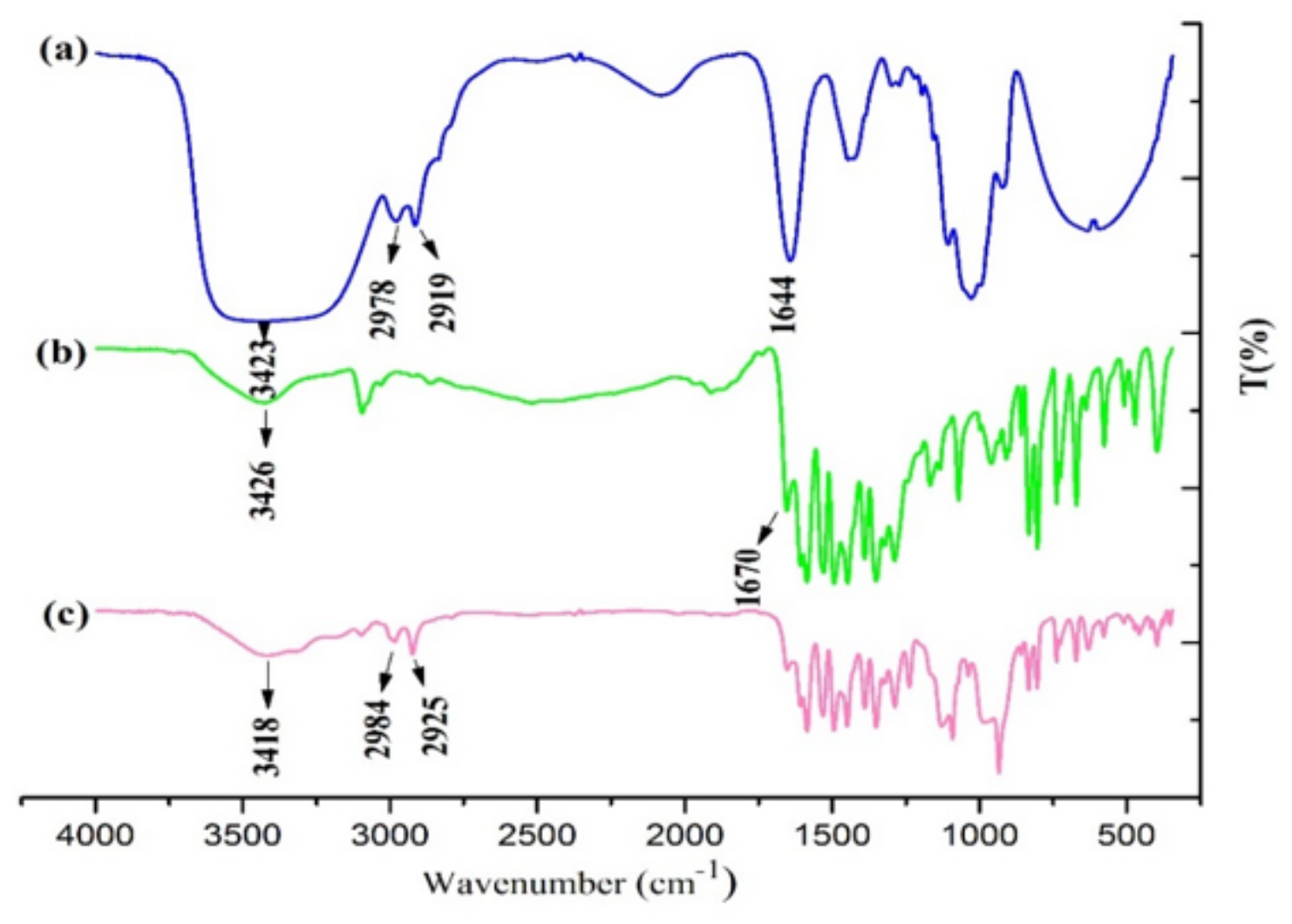

Figure 4

FTIR spectra of (a) formaldehyde, (b) alizarin yellow-GG, (c) formaldehyde mixed with alizarin yellow-GG. 


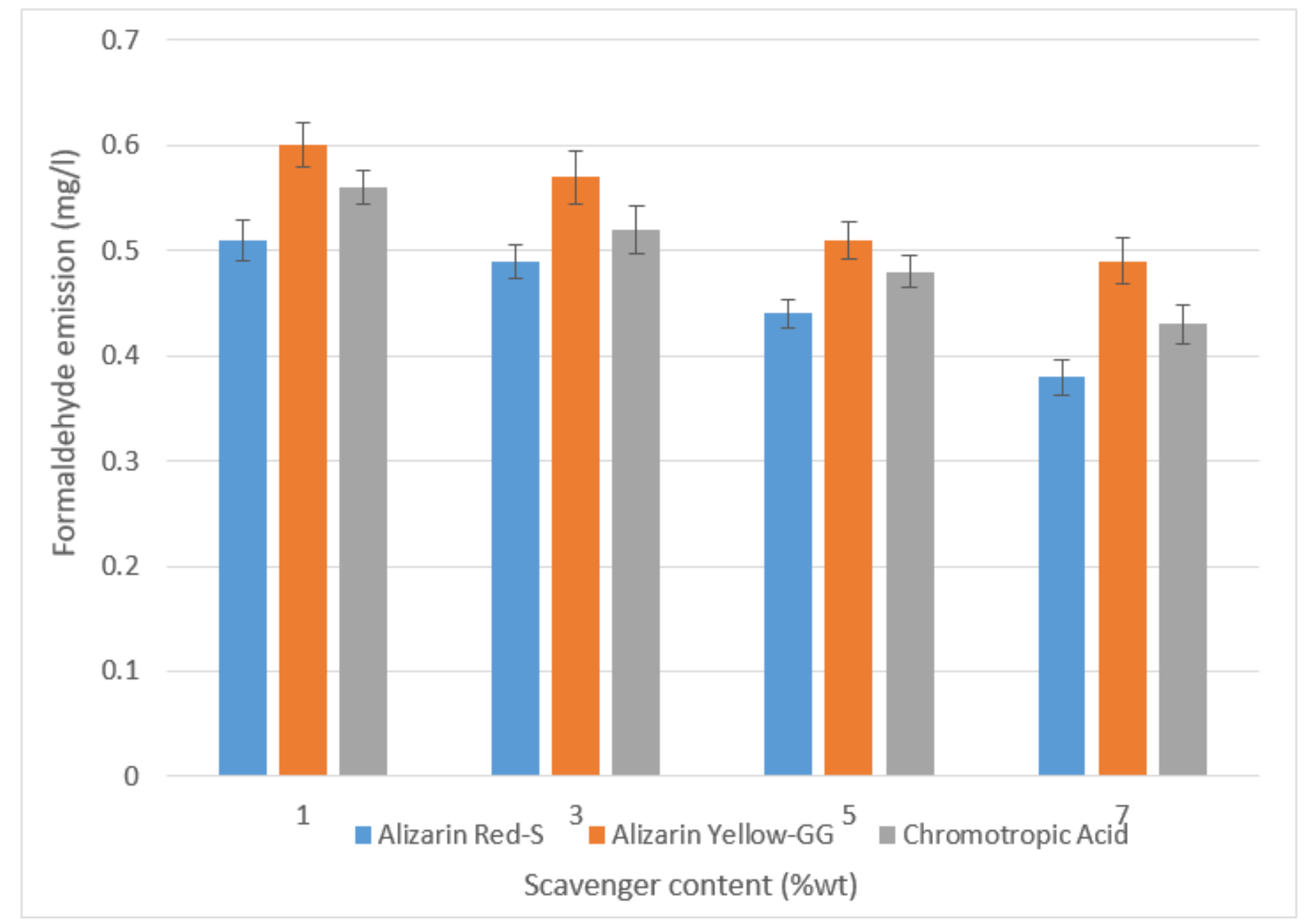

Figure 5

Formaldehyde emission of the particleboards depending on the scavenger type and content 

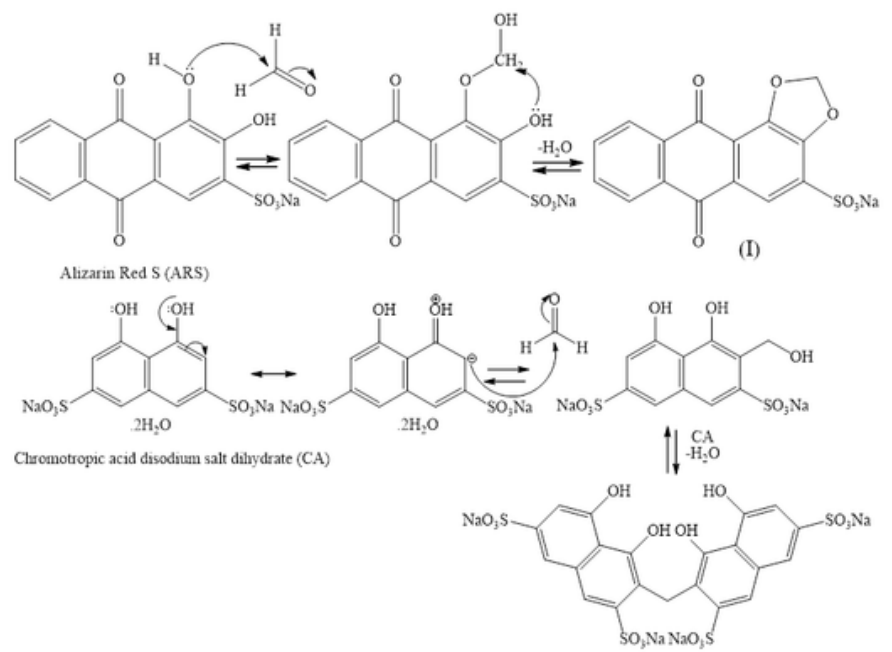

(II)
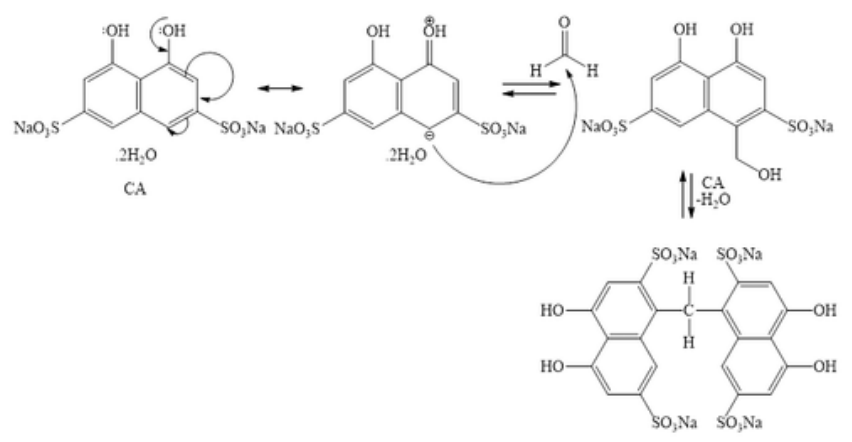

(III)
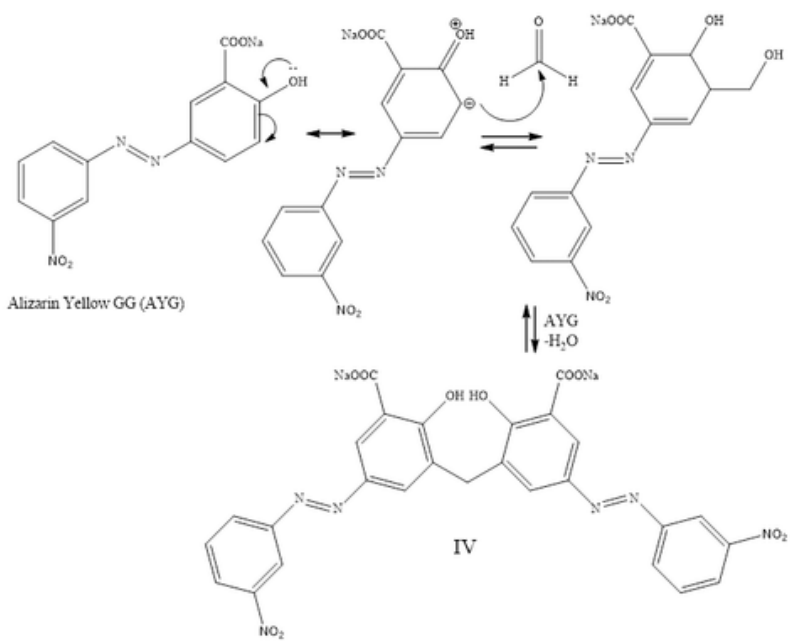

Figure 6

Scheme of proposed mechanism between scavengers and formaldehyde 


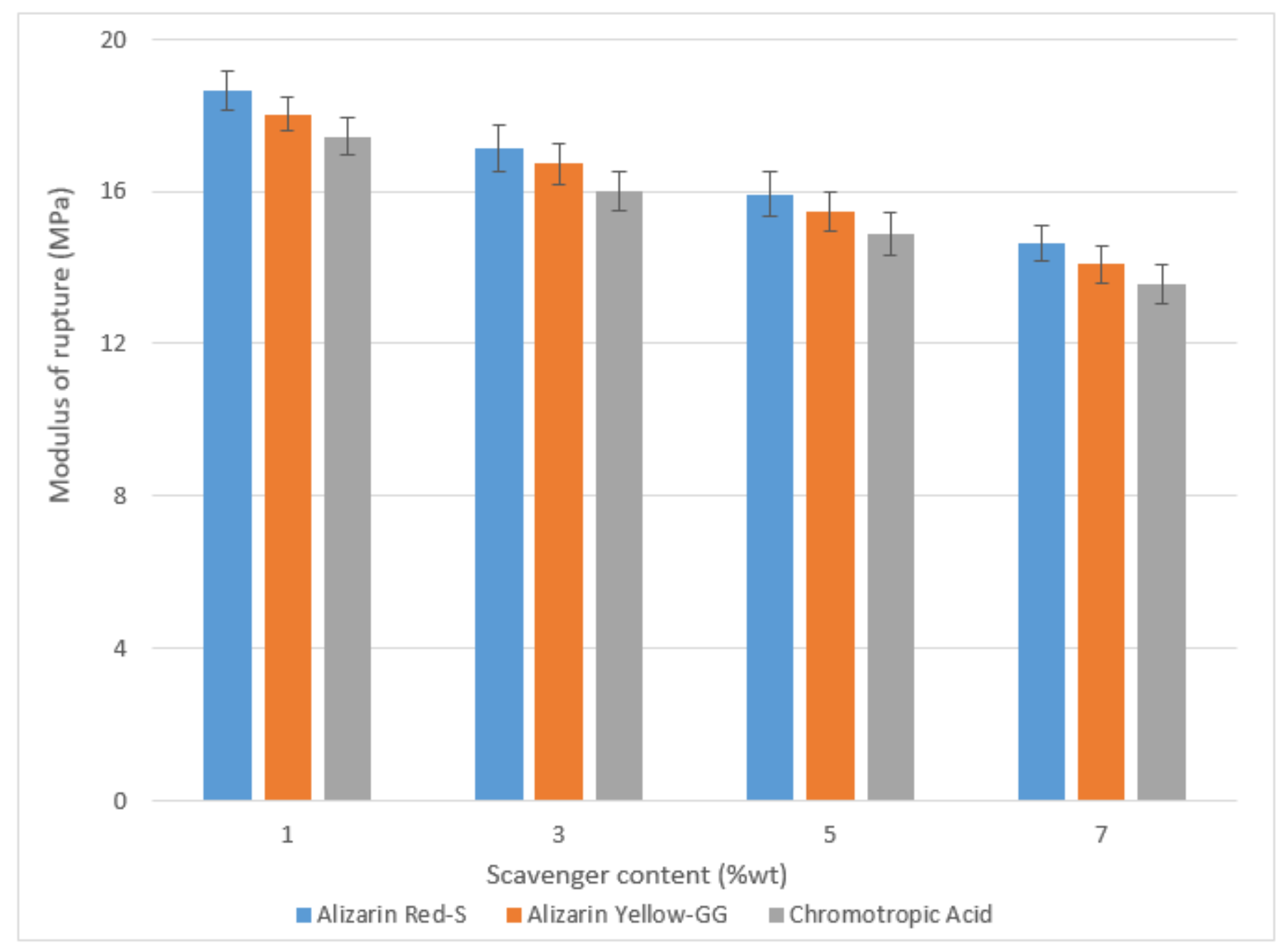

Figure 7

Modulus of rupture of the particleboards depending on the scavenger type and content 


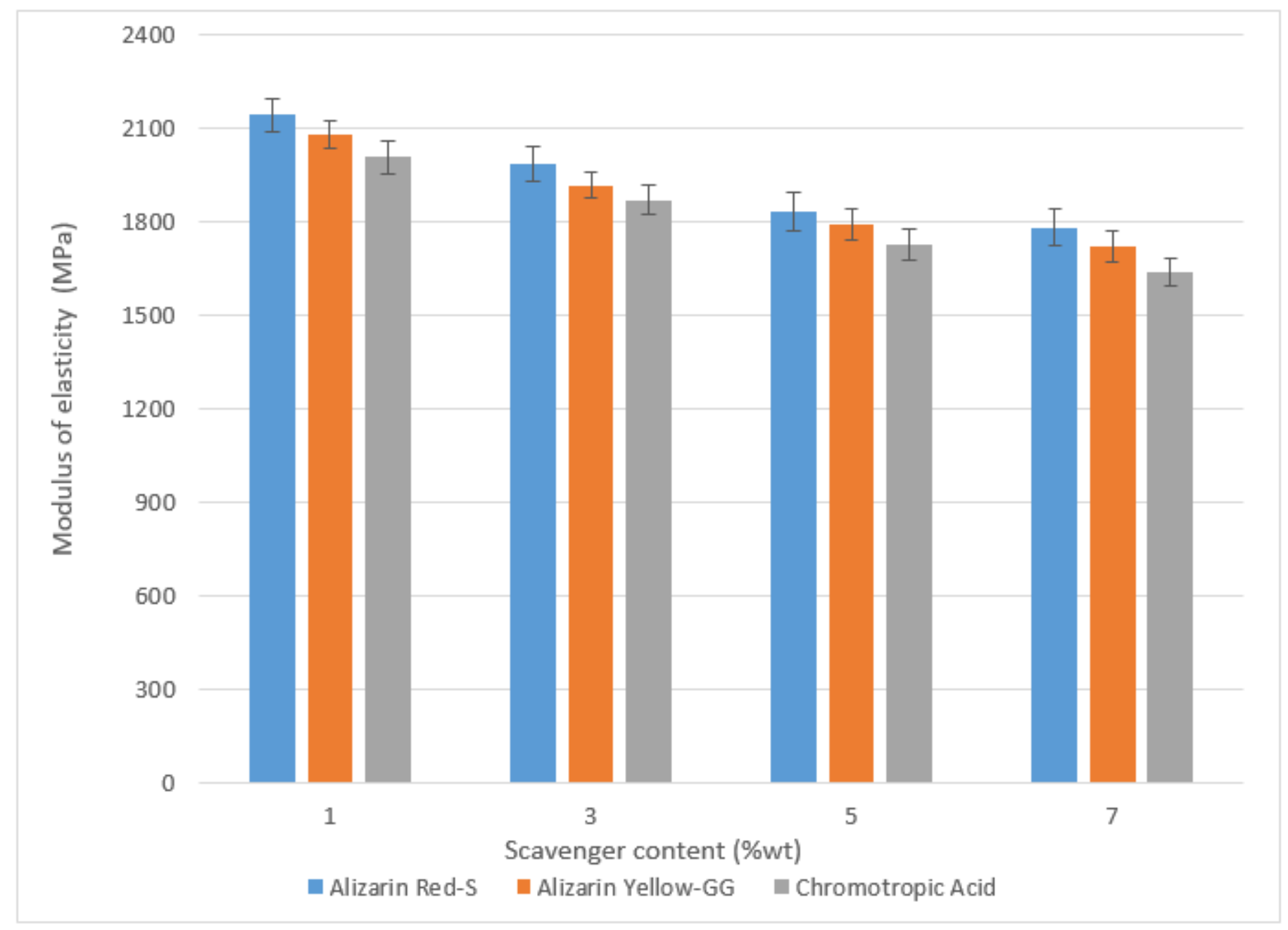

Figure 8

Modulus of elasticity of the particleboards depending on the scavenger type and content 


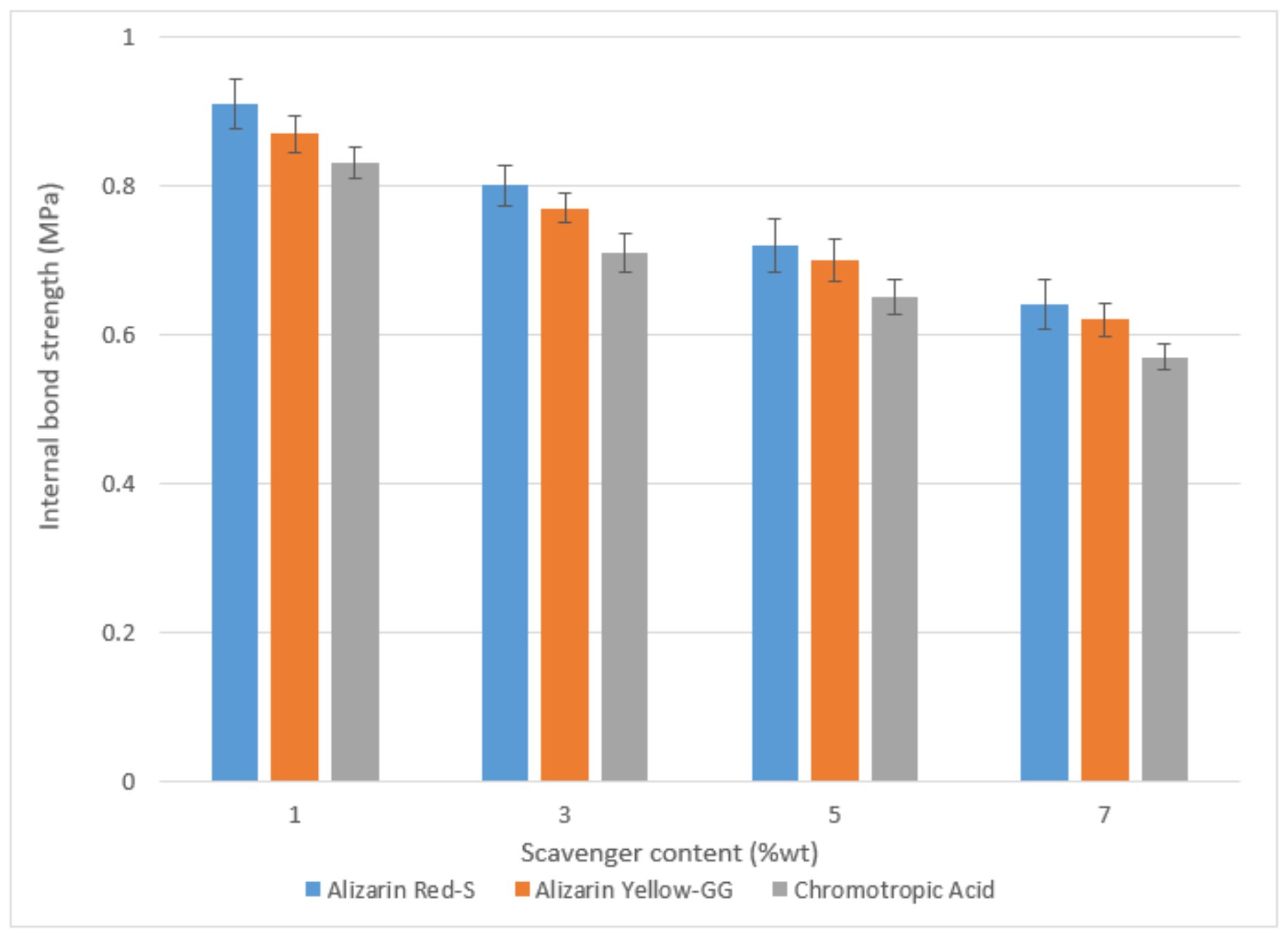

Figure 9

Internal bond strength of the particleboards depending on the scavenger type and content 


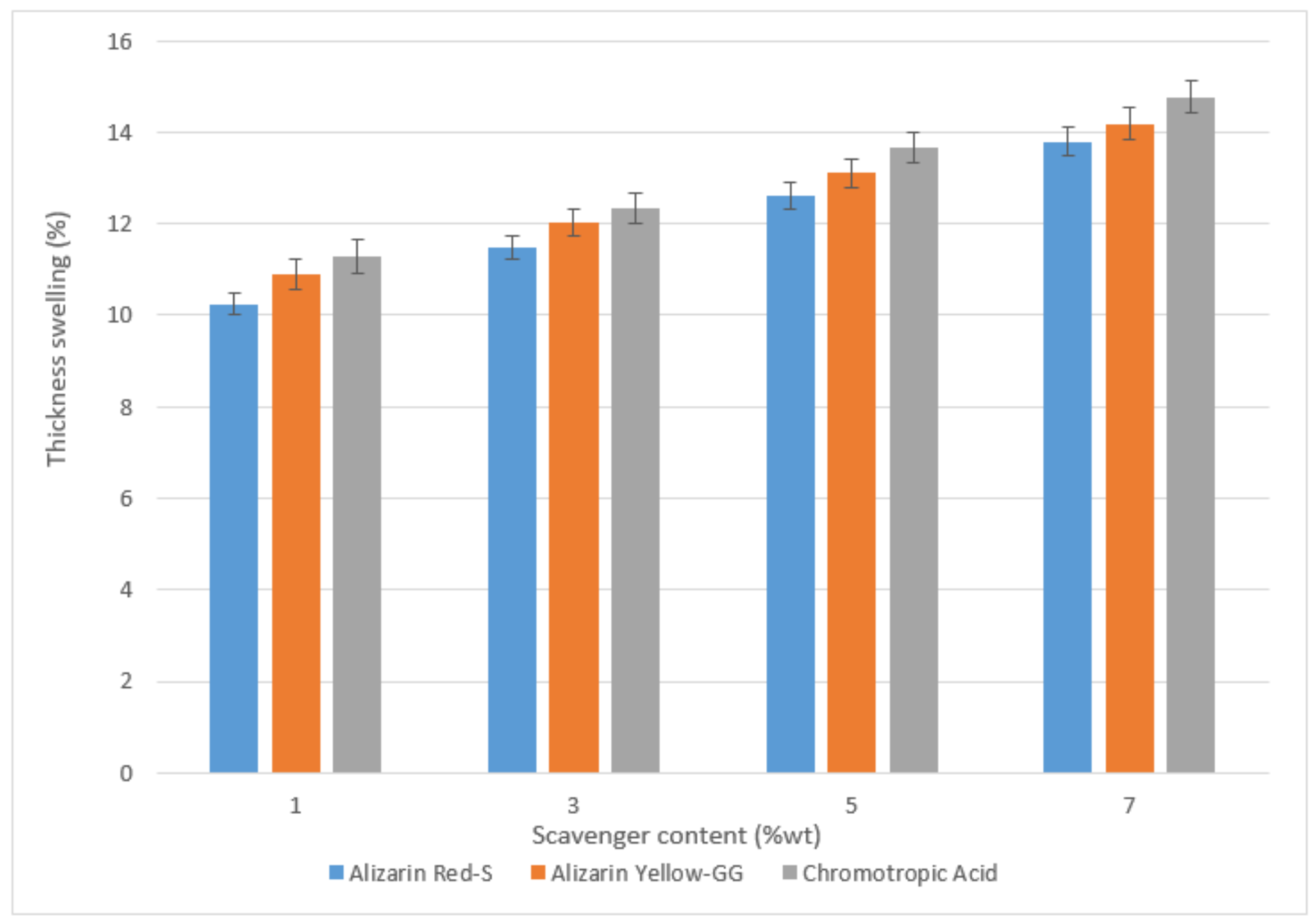

Figure 10

Thickness swelling of the particleboards depending on the scavenger type and content 


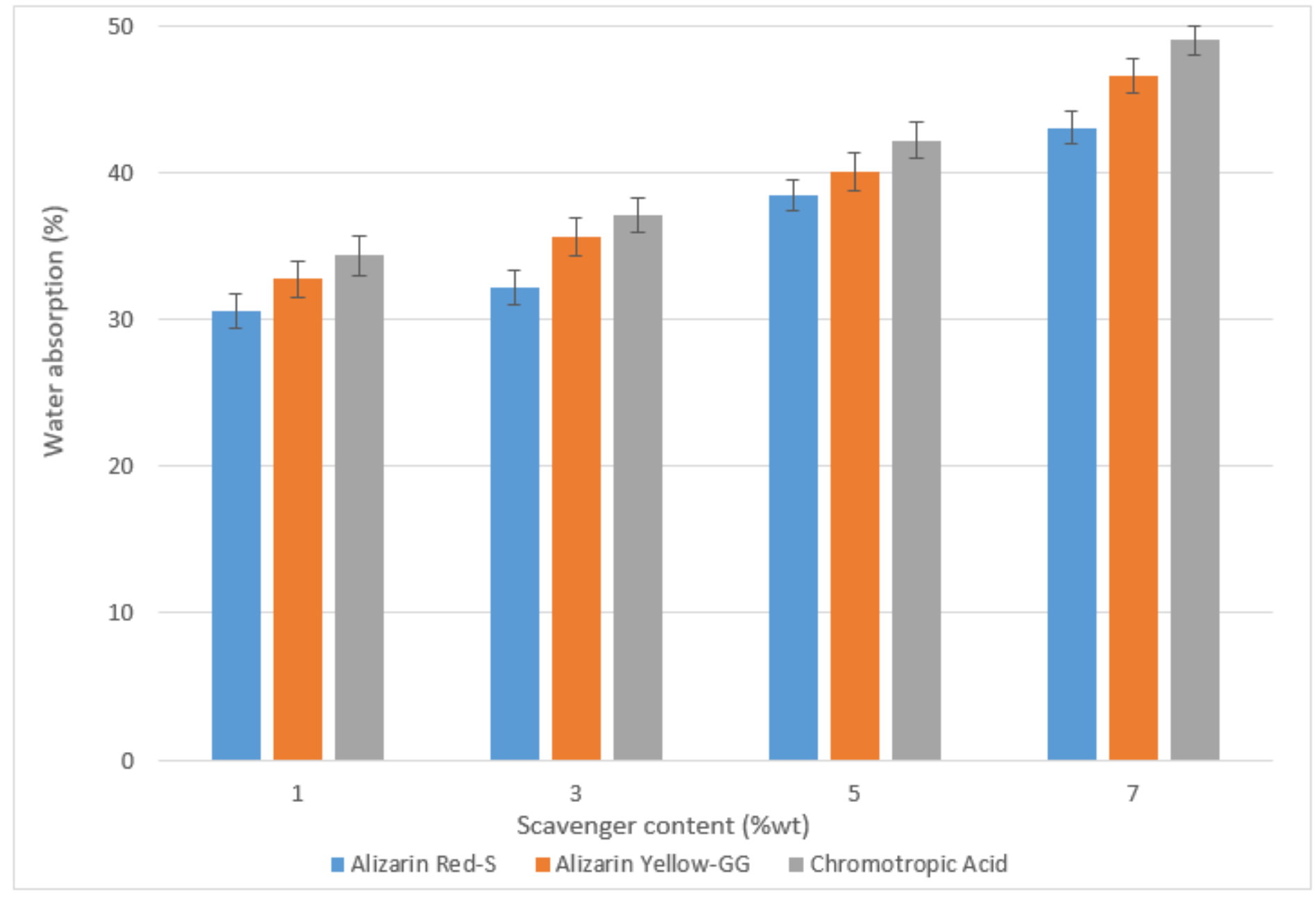

Figure 11

Water absorption of the particleboards depending on the scavenger type and content 